\title{
Injection parameters optimization of crosslinked polymer flooding by genetic algorithm
}

\author{
Peiqing Lian*, Linlin Li, Taizhong Duan \\ Petroleum Exploration and Production Research Institute, Sinopec, Beijing 100083, P. R. China
}

(Received July 2, 2018; revised August 1, 2018; accepted August 5, 2018; available online August 30, 2018)

Citation:

Lian, P., Li, L., Duan, T. Injection

parameters optimization of crosslinked

polymer flooding by genetic algorithm.

Advances in Geo-Energy Research, 2018, 2(4): 441-449, doi:

10.26804/ager.2018.04.08.

Corresponding author:

*E-mail: lianpq.syky@ sinopec.com

Keywords:

Enhanced oil recovery

crosslinked polymer flooding

genetic algorithm

fitness function

\begin{abstract}
:
The crosslinked polymer flooding, which is developed on the basis of polymer flooding, is a new type of flooding technology. As an EOR method, cross-linked polymer flooding has become a research hotspot. In the process of cross-linked polymer flooding, if the concentrations of the polymer and the crosslinking agent are small, the viscosity of the solution is low, and it will not achieve the oil displacement effect. Meanwhile, if the concentrations of the polymer and crosslinking agent are large, the viscosity of the solution is high, it needs high pressure to drive it flowing in the formation. Further, with the increasing injection of chemical agents, the contradiction between reduced production and increased cost has presented. The performance of crosslinked polymer flooding depends on the interaction of these two factors. Therefore, the concentrations of polymer and crosslinking agent should be optimized. In this paper, an optimal design method is proposed by using genetic algorithm with global optimization characteristics algorithm, combining with the chemical flooding numerical simulation software UTCHEM, the concentrations of the chemical agents are optimized. Firstly, the cumulative oil production is calculated by numerical simulation software UTCHEM, then the concentrations of the chemical agents are randomly generated by the genetic algorithm in the encoding process, and the fitness function takes the profit of cross-linked polymer flooding. Given a set of initial values, through crossover and mutation of population, optimized injection concentrations of the polymer and cross-linking agent are obtained by the multi-generational calculation.
\end{abstract}

\section{Introduction}

The performance of crosslinked polymer technology is characterized by adding a small amount of cross-linking agent into the low concentration of polymer solution to form the cross-linked polymer flooding system. This system with significant economic and social benefits is conducive to increase the viscosity of the displacing agent, to improve heat resistance and salt tolerance, and to reduce the cost of displacing agent (Mody et al., 1988; Zhou et al., 2007; Shen et al., 2010; He et al., 2015; Liu et al., 2016; Huang et al., 2017). Compared with polymer flooding, crosslinked polymer flooding can further improve oil recovery, which can add 5\%-15\% more than that of polymer flooding (Albonico et al., 1995; Song et al., 2002; Wei, 2007; Liu et al., 2011; Yang et al., 2014).

Many scholars have studied the mechanism of crosslinked polymer flooding (Shriwal and Lane, 2012; Brattekas et al., 2015; Lenchenkov et al., 2018). Himes et al. (1994) developed a new, environmentally friendly polymer for the well completion and stimulation treatments where a premium is placed on maximizing effectiveness while minimizing formation damage. This new polymer is used in many operational areas such as high-permeability fracturing, gravel packing, zonal isolation pills, spacer pills. Jiang et al. (2008) measured the gelation, flow ability and viscosity elasticity for the chromiumorganic cross-linked polymer solution by laboratory methods, and its effects of blocking and oil displacement are evaluated for NB 35-2 field. Jayakumar and Lane (2013) developed a new low-concentration, low-viscosity delayed-crosslink polymer gel system for water shutoff in small aperture features in higher temperature oil and gas reservoirs. The gel employs hydrolyzed polyacrylamide (HPAM) and Polyethyleneimine (PEI) crosslinker. Yang et al. (2014) used cross-linked polymer and microspheres-polymer composite flooding to research the effect of chemical system composition, displacement speed, and injection volume during polymer flooding by physical simulation experiments, and to optimize injection parameters of composite system. Zheng et al. (2016) used computed tomography (CT) technique to carry out the crosslinked 
polymer flooding experiment, and the tracking scanning of the process of crosslinked polymer flooding was used for rebuilding the pore structure of dry core and migration feature images of crosslinked polymer at different displacement time and different locations in the core.

While doing physical simulation experiments, the numerical simulation of crosslinked polymer flooding was carried out (Xie et al., 2007; Fakher et al., 2018; Li et al., 2018). Pope et al. $(1978,1999)$ added the crosslinked polymer flooding model into UTCHEM software. Lian et al. (2010) studied the mechanism of crosslinked polymer flooding, reviewed and discussed the research progress of crosslinked polymer flooding and its numerical simulation in high temperature and high salt reservoir. Zhang et al. (2010) determined an optimized mathematic model for optimizing the parameters of crosslinked polymer flood slug injection. It is transformed into programming problem with nonlinear restraint, and the problem is solved by using fmincon optimization module from Matlab optimization tool box. The result is verified by using numerical simulation method. Yuan et al. (2014) presented a three-dimension, two-phase and five-component (oil, water, polymer, cross-linked polymer, and cross-linker) mathematical model according to the profile control and flooding mechanism of cross-linked polymer flooding. Based on IMPES method, a more efficient and more stable Douglas difference scheme was proposed which used the step-by-step reduced-order idea to solve a model. Ebaga-Ololo and Chon (2017) proposed an efficient recovery factor prediction tool at different injection stages of two polymer slugs during polymer flooding using an artificial neural networks (ANN); with an acceptable correlation coefficient, the proposed ANN tool was able to predict the recovery factor with errors of $<1 \%$.

During the crosslinked polymer flooding, if the injection volume of polymer and crosslinking agent are small, the amount of cross-linked polymer generated from the reaction is also small, and it has no effect on improving displacement efficiency. If there are too much chemical agents, the amount of cross-linked polymer is large, and it requires high displacement pressure to drive fluid in the formation, meanwhile, it will result in production cost increase. Therefore, it is a key problem to select a reasonable injection concentration in the process of cross-linking polymer flooding (Wang et al., 2002; Yin et al., 2013; El-Karsani et al., 2014). Genetic algorithm (GA) is one of the key technologies in modern intelligent computing and has been widely used in the field of reservoir development ( $\mathrm{Li}$ et al., 2006; Liu et al., 2008; Li et al., 2012). Genetic algorithms operate directly on the structure of the object, and there is no derivation and limited function continuity. It is global internal implicit parallelism and has better optimization ability. Besides, it uses the probability optimization methods, automatic acquisition and guidance to optimize the search space and adaptively adjust the search direction (Montes et al., 2001; Carpenter, 2008; Wood, 2018). In this section, a new method to optimize the chemical injection concentrations is proposed by mean of the genetic algorithm and the cross-linked polymer flooding model, it has significant meaning in the injection parameter design.

\section{Mathematical model of crosslinked polymer flooding}

The crosslinked polymer flooding model is a complex component one, which mainly includes the mass conservation equation and the pressure equation, and the crosslinking reaction equation of the crosslinking agent and the polymer in the subsurface (Cao et al., 2015). This paper mainly uses the crosslinked polymer flooding model based on UTCHEM software.

\subsection{The cross-linked polymer model}

The kinetics of polymer/chromium chloride gel are simulated, and a component model is used. There are seven componts in this model, namely water, oil, polymer, chloride, $\mathrm{Cr}(\mathrm{III})$, gel and hydrogen, where gel is the formed crosslinked polymer. According to Darcy's law, the mass conservation equation of total concentration of the $k^{\text {th }}$ component can be writen as (Pope et al., 1999):

$$
\begin{gathered}
\frac{\partial}{\partial t}\left(\phi \tilde{C}_{k} \rho_{k}\right)+\operatorname{div}\left[\sum_{l=1}^{n_{p}} \rho_{k}\left(C_{k l} u_{l}-\tilde{D}_{k l}\right)\right]=Q_{k} \\
k=1,2, \cdots, n_{c}
\end{gathered}
$$

Where $n_{c}$ is the component number; $n_{p}$ is the phase number, water or oil; $C_{k l}$ is the concentration of component $k$ in phase $l ; \tilde{C}_{k}$ is the overall volume of component $k$ in per unit pore volume; $\tilde{D}_{k l}$ is dispersive flux of component $k$ in phase $l$, which adhere to Fick's law; $Q_{k}$ is the injection/production rate for component $k$ per bulk volume; $\phi$ is the porosity of reservoir; $\rho_{k}$ is the density of pure component $k$ at a reference phase pressure.

The definition of capillary pressure in terms of the reference phase pressure (phase 1) has been used, namely $P_{c l 1}$ $=P_{l}-P_{1}$. The pressure equation is developed by summing the mass balance equations of volume-occupying components. Substituting Darcy's law for the phase flux terms, the pressure equation is:

$$
\begin{gathered}
\phi C_{t} \frac{\partial P_{1}}{\partial t}+\nabla \overline{\bar{K}} \lambda_{T} \nabla P_{1}= \\
-\nabla \sum_{l=1}^{n_{p}} \overline{\bar{K}} \lambda_{L} \nabla D+\nabla \sum_{l=2}^{n_{p}} \overline{\bar{K}} \lambda_{L} \nabla P_{c l 1}+\sum_{k=1}^{2} Q_{k}
\end{gathered}
$$

Where $C_{t}$ is the total compressibility; $D$ is the vertical depth; $\overline{\bar{K}}_{k l}$ is the dispersion tensor; $\lambda_{L}$ is the mobility of phase $l ; \lambda_{T}$ is the total mobility, $\lambda_{T}=\sum_{l=1}^{n_{p}} \lambda_{L}$.

\subsection{Cross-linking reaction equations}

\subsubsection{Kinetics of cross-linking system}

Simultaneous injection of polymer and crosslinker into the reservoir is studied. $\mathrm{The} \mathrm{Cr}$ (III) for the gelation process can be generated in situ by redox reaction between $\mathrm{Cr}(\mathrm{VI})$ and nitrite. Polymer molecules are crosslinked by $\mathrm{Cr}(\mathrm{III})$, which is one of 
the most widely used crosslinkers (Nguyen et al., 2004; Luo et al., 2005; Lu et al., 2015).

$$
\begin{gathered}
\mathrm{Cr}_{2} \mathrm{O}_{7}{ }^{2-}+3 \mathrm{NO}_{2}{ }^{-}+8 \mathrm{H}^{+} \stackrel{\eta}{\rightarrow} 2 \mathrm{Cr}^{3+}+3 \mathrm{NO}_{3}{ }^{-}+4 \mathrm{H}_{2} \mathrm{O} \\
\text { Polymer }+n \mathrm{Cr}^{3+}+m \mathrm{H}_{2} \mathrm{O} \rightleftharpoons \mathrm{Gel}+3 n \mathrm{H}^{+}
\end{gathered}
$$

The kinetics can be express as follow:

$$
\frac{d[\mathrm{Gel}]}{d t}=-\frac{1}{n} \frac{d\left[\mathrm{Cr}^{3+}\right]}{d t}=\frac{1}{n} \cdot \frac{k \cdot\left[\mathrm{Cr}^{3+}\right]^{a}[\text { Polymer }]^{b}}{\left[\mathrm{H}^{+}\right]^{c}}
$$

Where [Polymer], $\left[\mathrm{Cr}^{3+}\right],[\mathrm{Gel}],\left[\mathrm{H}^{+}\right]$are denote to the concentration of polymer, chromium ions and hydrogen ion; $\eta$ is the reaction constant for gel; $a, b, c$ are the reaction exponents.

\subsubsection{Viscosity model}

The viscosity of an aqueous solution (phase 1) containing gel is modeled by using the Flory-Huggins equation (Flory, 1941; Huggins, 1941).

$$
\begin{aligned}
\mu_{1}=\mu_{w}[1 & +\left(A_{p 1} C_{p}+A_{p 2} C_{p}{ }^{2}+A_{p 3} C_{p}{ }^{3}\right) C_{S E P}^{S_{P}} \\
& \left.+A_{g 1} C_{g}+A_{g 2} C_{g}{ }^{2}\right]
\end{aligned}
$$

Where $C_{p}$ is the polymer concentration; $C_{g}$ is the gel concentration; $\mu_{w}$ is the water viscosity; $A_{p 1}, A_{p 2}$, and $A_{p 3}$ are constant parameters; $A_{g 1}, A_{g 2}$ are constant parameters; $C_{S E P}$ is effective salinity for polymer; salinity and hardness. $S_{p}$ is the slope of $\left(\mu_{1}^{0} / \mu_{w}-1\right)$ vs. $C_{S E P}$ on a $\log -\log$ plot; $\mu_{1}^{0}$ is the initial viscosity of phase 1 .

\subsubsection{Gel adsorption}

Gel adsorption model is established by using a "Langmuirtype" isotherm to correlate adsorbed concentration with the aqueous-phase concentrations.

$$
\hat{C}_{g}=\frac{a_{1} C_{g}}{1+b_{1} C_{g}}
$$

Where $a_{1}, b_{1}$ are the constants; $\hat{C}_{g}$ is the adsorbed gel concentration.

The effect of gel on aqueous-phase permeability reduction is taken into account through a residual resistance factor.

$$
R_{R F}=1+\frac{\left(R_{R F_{\max }}-1\right) a_{2} C_{g}}{1+b_{2} C_{g}}
$$

Where $a_{2}, b_{2}$ are the constant parameters; $R_{R F_{\max }}$ is the maximum residual resistance.

\subsection{Solving method}

The resulting flow equations are solved by using a blockcentered finite-difference scheme. The solution method is implicit in pressure and explicit in concentration. After the equations are solved, the total production of oil can be calculated.

\section{Polymer and crosslinker concentration opti- mization}

A genetic algorithm is a metaheuristic inspired by the process of natural selection that belongs to the larger class of evolutionary algorithms. Genetic algorithms are commonly used to generate high-quality solutions to optimize and search problems by relying on bio-inspired operators such as selection, crossover and mutation (Melanie, 1998; Wang and Cao, 2002). We use genetic algorithm to optimize the input parameters of crosslinked polymer flooding.

\subsection{Encoding}

For simplification, taking real number coding as an example, the form of the gene string $X_{i}(i=1,2, \ldots, N)$ is $\left(a_{i 1}\right.$, $\left.a_{i 2}, \cdots, a_{i n}\right)$, where, $n$ is the dimension of the solution space, and $N$ is the population size. The chromosome is consisted of various parameters which affect the oil well production rate, including the injection volume, the polymer concentration, the chromium ion concentration, the formed gel concentration, and so on.

\subsection{Fitness function}

In the process of the adaptability evaluation of each individual in the group, the objective function of the problem to be optimized is often used directly. The objective fitness function is set to be the profit of the cross-linked polymer flooding.

$$
G_{t}=\sum_{i=1}^{t} P_{i} Q_{i} \frac{1}{(1+s)^{i}}
$$

Where, $Q_{i}$ is oil production rate on Day $i, \mathrm{~m}^{3} / \mathrm{d} ; P_{i}$ is the oil price on Day $i, \$ / \mathrm{m}^{3}$; $\mathrm{s}$ is the interest rate; $t$ is the production time, days.

The total cost of $G_{s}$ is simply expressed as the sum of the chemical costs and the usual operating costs:

$$
G_{s}=C_{H} t_{i n j}+C_{M} t
$$

Where $C_{H}$ is the daily cost of the Chemical agents (polymers and crosslinking agent), $\$ / \mathrm{d} ; C_{M}$ is the daily operating costs, $\$ / \mathrm{d} ; t_{i n j}$ is the chemical injection time; $t$ is the production time.

The Net income is $R$ :

$$
R=G_{t}-G_{s}=\left[\sum_{i=1}^{t} P_{i} Q_{i} \frac{1}{(1+s)^{i}}\right]-\left(C_{H} t_{i n j}+C_{M} t\right)
$$

If the oil price remains unchanged, the interest rate $s=0$, the above formula becomes:

$$
R=P \sum_{i=0}^{t} Q_{i}-\left(C_{H} t_{i n j}+C_{M} t\right)
$$

The fitness function is taken as $R$. In this case, in the Eq. (12), the daily cost of chemical agents is related to the injection concentrations, and those parameters are randomly generated by the genetic algorithm in the coding process. The 


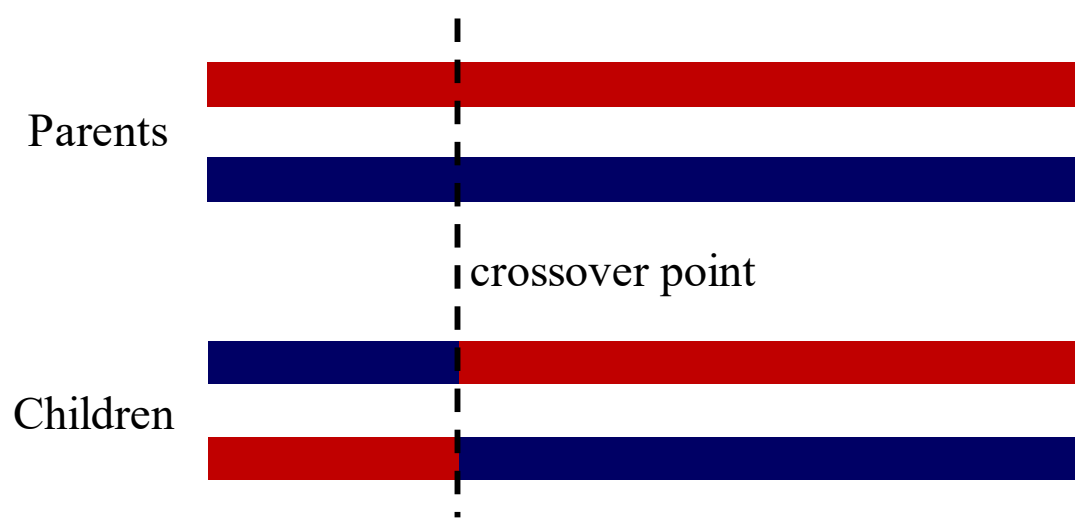

Fig. 1. The process of crossover.

cross-linked polymer flooding model described above has been used to obtain the cumulative oil production by the numerical simulation, and the cumulative oil production is related to the chemical injection concentration.

\subsection{Selection}

Selection is the stage in which individual chromosomes are chosen from a population for later breeding. The generic selection procedure is implemented as follows:

1) The fitness function is evaluated for each individual, providing fitness values, which are then normalized.

2) The population is sorted by descending fitness values.

3) Accumulated normalized fitness values are computed. The accumulated fitness value of an individual is the sum of its own fitness value plus the fitness values of all the previous individuals.

4) A random number $R$ between 0 and 1 is chosen.

5) The selected individual is the last one whose accumulated normalized value is greater than or equal to $R$.

\subsection{Crossover}

Crossover is a genetic operator used to combine the genetic information of two parents to generate new offspring. It is one way to stochastically generate new solutions from an existing population, and analogous to the crossover that happens during sexual reproduction in biology. Solutions can also be generated by cloning an existing solution, which is analogous to asexual reproduction. Newly generated solutions are typically mutated before being added to the population.

In the crossover process, a point on both parents' chromosomes is picked randomly, and designated a 'crossover point', as shown in Fig. 1. Bits to the right of that point are swapped between the two parent chromosomes. This results in two offspring, each carrying some genetic information from both parents.

\subsection{Mutation}

Mutation is a genetic operator used to maintain genetic diversity from one generation of a population of genetic algorithm chromosomes to the next. It is analogous to biological mutation. Mutation alters one or more gene values in a chromosome from its initial state. In mutation, the solution may change entirely from the previous solution. Hence GA can come to a better solution by using mutation.

The purpose of mutation is preserving and introducing diversity. Mutation allows the algorithm to avoid local minima by preventing the population of chromosomes from becoming too similar to each other, thus slowing or even stopping evolution. This reasoning also explains the fact that most GA systems avoid only taking the fittest of the population in generating the next but rather a random (or semi-random) selection with a weighting toward those that are fitter.

\section{Case analysis}

\subsection{Theoretical model establishment}

The pattern of " 4 injectors and 1 producer" is used to optimize the injection parameters of "polymer + crosslinker" flooding. The network is divided into $N_{x} \times N_{y} \times N_{z}=15 \times 15$ $\times 2, D_{x}=D_{y}=30 \mathrm{~m}, D_{z}=5 \mathrm{~m}$. The well pattern is shown in Fig. 2, in which the production well is located at the plane grid $(8,8)$, while the four injectors are respectively at $(1,1)$, $(1,15),(15,1),(15,15)$, and the well perforation is through the entire reservoir thickness. The top depth of the reservoir is $2,100 \mathrm{~m}$, the initial pressure is $20.0 \mathrm{MPa}$, and the porosity $\phi$ is 0.2 . The first layer permeability is separately $K_{x}=K_{y}=$ $0.5 \mu \mathrm{m}^{2}, K_{z}=0.01 \mu \mathrm{m}^{2}$, while the second layer is separately $K_{x}=K_{y}=1.5 \mu \mathrm{m}^{2}, K_{z}=0.015 \mu \mathrm{m}^{2}$. The viscosity of crude oil is $2.0 \mathrm{mPa} \cdot \mathrm{s}$, and the density is $0.81 \mathrm{~g} / \mathrm{cm}^{3}$.

The injection volume of four injection wells are the same, which have a flow rate $20 \mathrm{~m}^{3} / \mathrm{d}$ and maximum bottom-hole pressure $25.0 \mathrm{MPa}$, while the production well has a flow rate $80 \mathrm{~m}^{3} / \mathrm{d}$ and minimum bottom-hole pressure 5.0 MPa. After water injection for 650 days, the cross-linked polymer flooding has been carried out, and 500 days later, the injection pattern is transferred back to water flooding. The total simulation time is 20 years. The parameters for crosslinker and polymer are show in Table 1. 


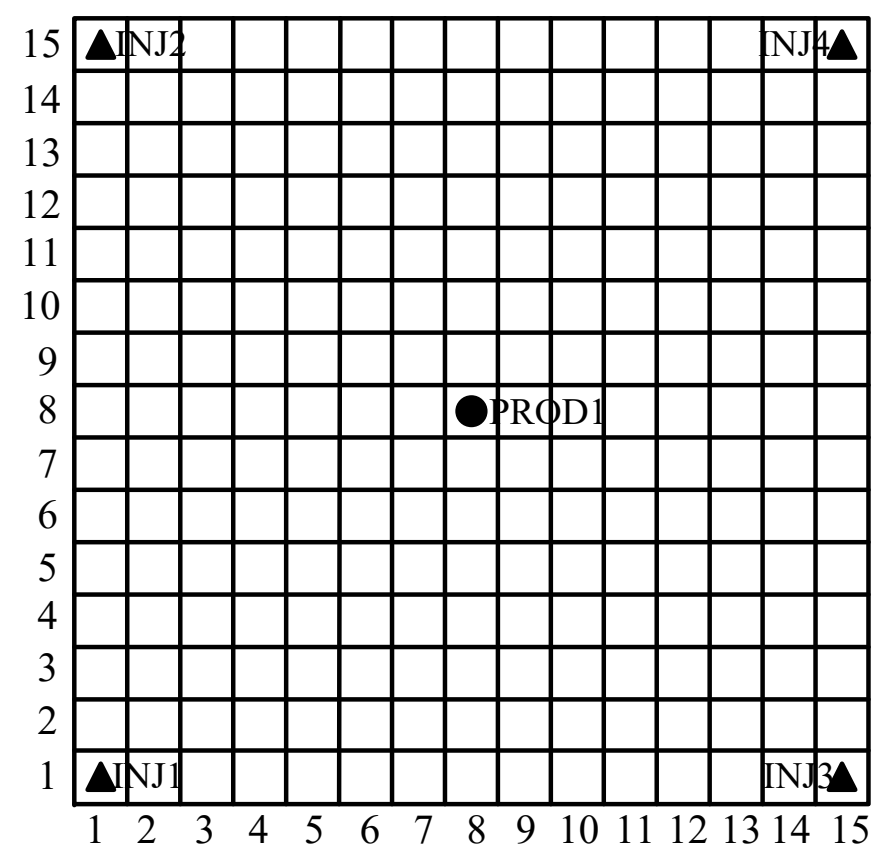

Fig. 2. Well pattern during numerical simulation.

Table 1. The parameters for crosslinker and polymer.

\begin{tabular}{ll}
\hline Parameter & Value \\
\hline$a$, dimensionless & 0.6 \\
$b$, dimensionless & 2.6 \\
$c$, dimensionless & 1.0 \\
$k$, mol/L & 15 \\
$n$, dimensionless & 4 \\
$A_{p 1}$, dimensionless & 85 \\
$A_{p 2}$, dimensionless & 2,500 \\
$A_{p 3}$, dimensionless & 2,400 \\
$A_{g 1}$, dimensionless & 0.008 \\
$A_{g 2}$, dimensionless & $2.7 \times 10^{-5}$ \\
$C_{S E P}$, meq/ml & 0.01 \\
$S_{P}$, dimensionless & 0.169 \\
$a_{1}$, dimensionless & 1510 \\
$b_{1}$, dimensionless & 139 \\
$a_{2}$, dimensionless & 0.06 \\
$b_{2}$, dimensionless & 0.10 \\
\hline
\end{tabular}

\subsection{Cross-linked polymer flooding simulation results}

When the chemical agents are injected, a large gel system with high viscosity is formed at the displacing front, which drives the oil flowing to the production well. Fig. 3 shows the concentration distribution of the gel at different production time. Because of the existence of the follow-up water flooding, the plug will continually move to the production wells. However, due to the pore adsorption and retention, the gel concentration gradually decreased. When the displacing front reaches the production wells, the residual gel will be produced with oil and water.

In Figs. 4-6, the water cut, the average reservoir pressure, and the recovery of water flooding, polymer flooding and crosslinked polymer flooding were compared. It can be seen that the crosslinked polymer flooding can greatly reduce the reservoir water saturation, and increase the reservoir pressure, and the recovery is $10 \%$ and $5 \%$ higher than that of water flooding and polymer flooding respectively. As a result, the cross-linked polymer flooding has an advantage over water flooding and polymer flooding.

\subsection{Injection parameter optimization}

The optimized range of polymer mass fraction is $0.05 \%$ $0.35 \%$, and the crosslinking agent mass fraction is optimized from $0.01 \%$ to $0.25 \%$. The prices and operating costs of the polymers and crosslinking agent used are shown in Table 2.

By adjusting the size of genetic parameters, such as group size, crossover probability, mutation probability, and maximum generation, etc., the genetic algorithm can be controlled to calculate the more accurate results by a relatively short period. Fig. 7 shows the relationship between the total profit and the genetic generation. It can be seen that, in the early stage of genetic algorithm calculation, the total profit increases greatly, but with the increase of the genetic generation, the curve trend tends to be gentle. During the calculation of 140 generations, the optimal concentrations of chemical agents injected can be 


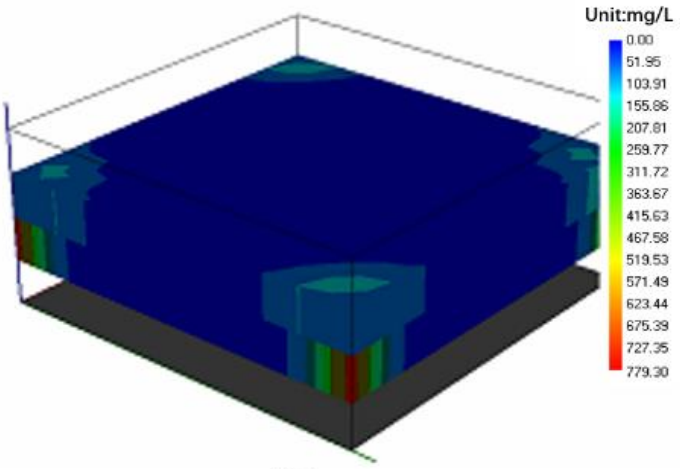

(a) 3 years

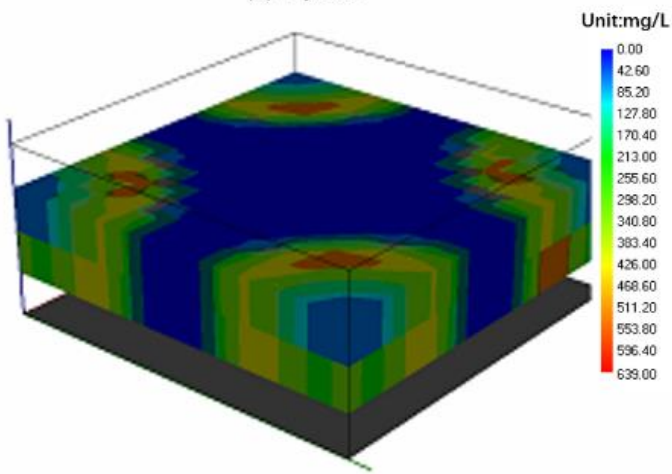

(c) 9 years

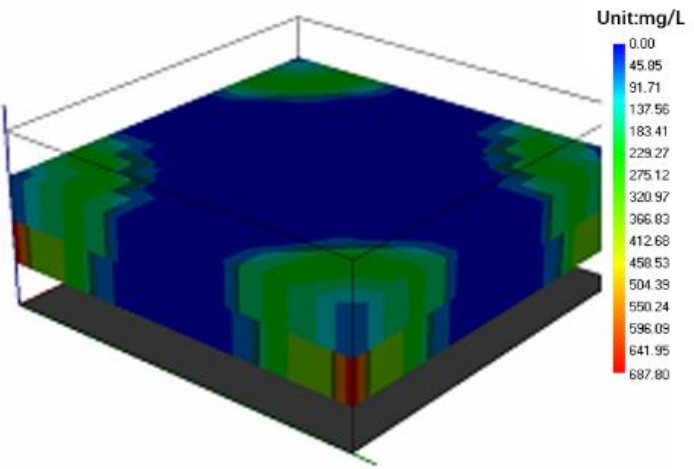

(b) 6 years

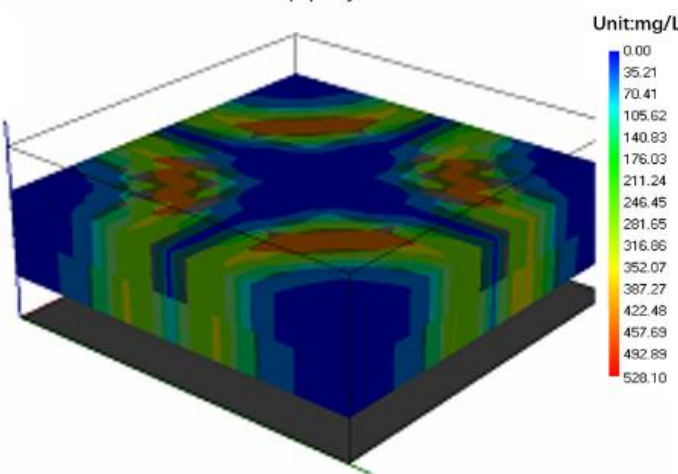

(d) 12 years

Fig. 3. Gel concentration at the production time of 3, 6, 9, and 12 years.

Table 2. Crude oil, chemical prices and operating cost.

\begin{tabular}{lllll}
\hline Item & Crude oil $\left(\$ / \mathrm{m}^{3}\right)$ & Polymer $(\$ / \mathrm{t})$ & Crosslinking agent $(\$ / \mathrm{t})$ & Operation $(\$ / \mathrm{t})$ \\
\hline Cost & 377.4 & 1,900 & 3,600 & 60 \\
\hline
\end{tabular}

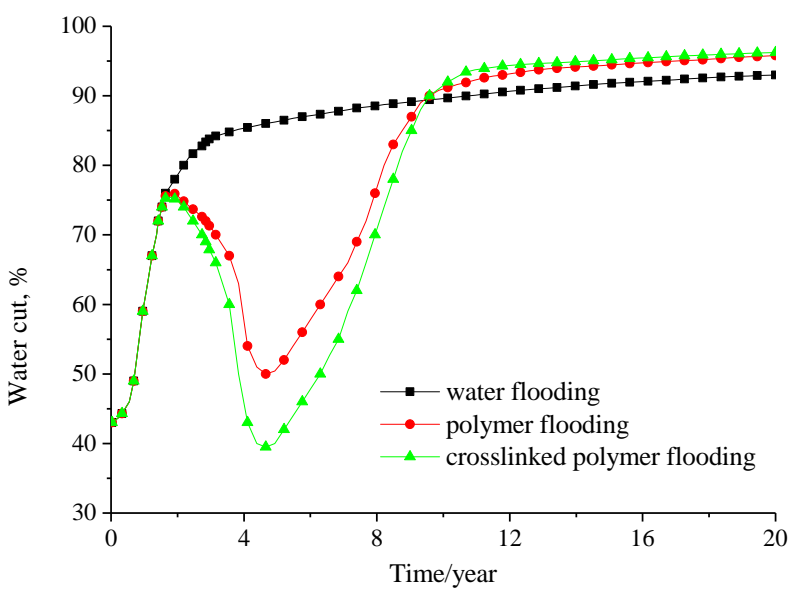

Fig. 4. Comparison of the water cut of water, polymer and crosslinked polymer flooding.

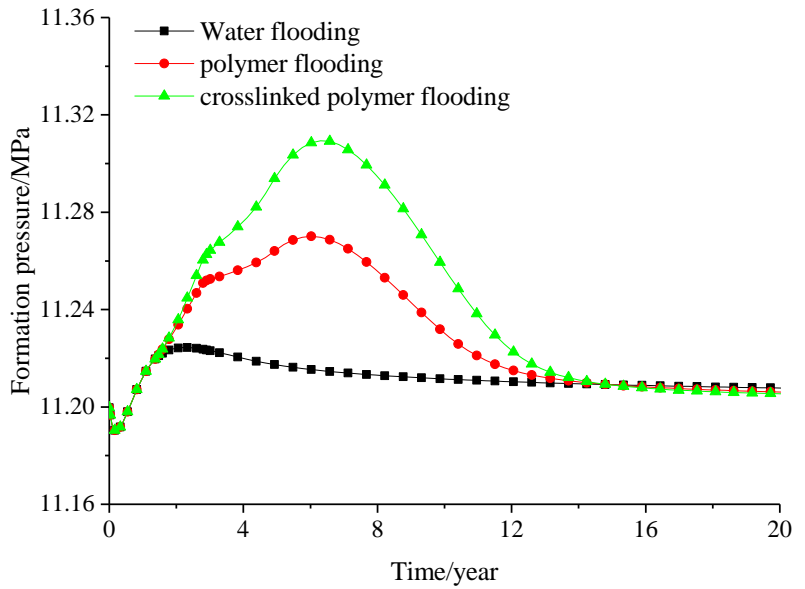

Fig. 5. Comparison of the average reservoir pressure of water, polymer and crosslinked polymer flooding. 
Table 3. Comparison of the results between optimal scheme and arbitrary scheme.

\begin{tabular}{llll}
\hline Data Item & Scenario 1 & Scenario 2 & Optimized scenario \\
\hline The concentration of polymer (\%) & 0.100 & 0.200 & 0.176 \\
The concentration of crosslinker (\%) & 0.050 & 0.150 & 0.081 \\
Amount of polymer (t) & 40.00 & 80.00 & 70.40 \\
Amount of crosslinking agent (t) & 20.00 & 60.00 & 32.40 \\
Total chemical costs (thd.\$) & 148.00 & 368.00 & 251.62 \\
Operating costs (thd.\$) & 438.00 & 438.00 & 438.00 \\
Cum. Oil production (thd. $\left.\mathrm{m}^{3}\right)$ & 159.53 & 160.96 & 169.01 \\
Recovery $(\%)$ & 39.39 & 39.74 & 41.73 \\
Total profit (mln.\$) & 59.62 & 59.94 & 63.09 \\
\hline
\end{tabular}

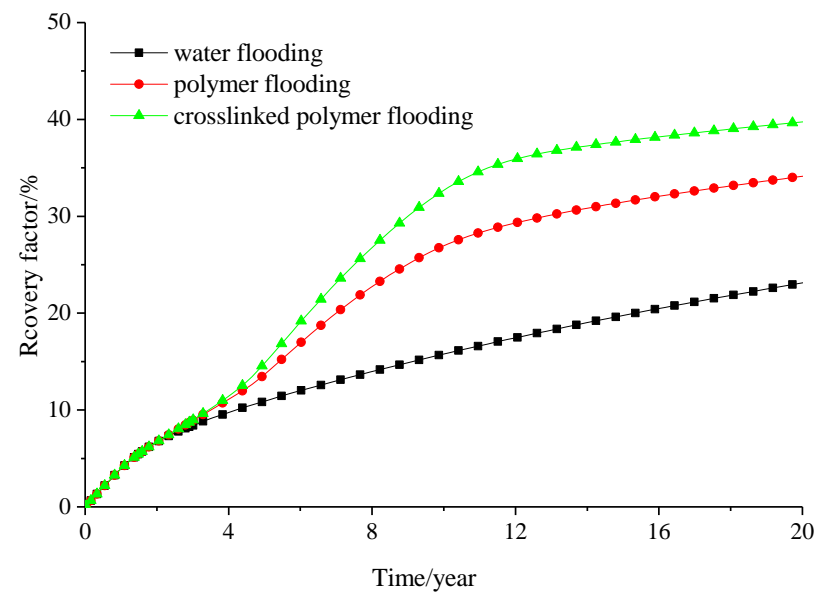

Fig. 6. Comparison of the recovery of water, polymer and crosslinked polymer flooding.

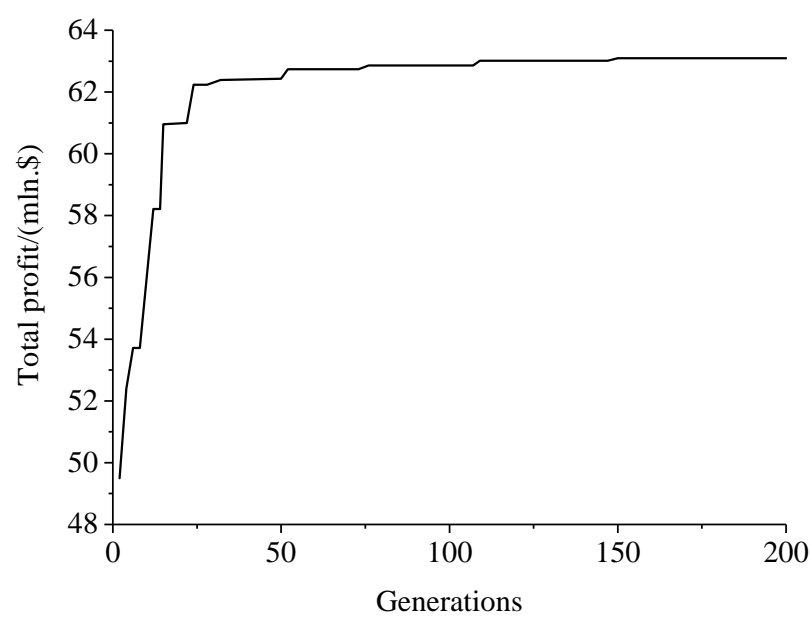

Fig. 7. The relation between total profit and genetic generations.

obtained. In this case, the optimal value of the polymer mass fraction is $0.186 \%$ and the optimal value of the crosslinker mass fraction is $0.081 \%$.

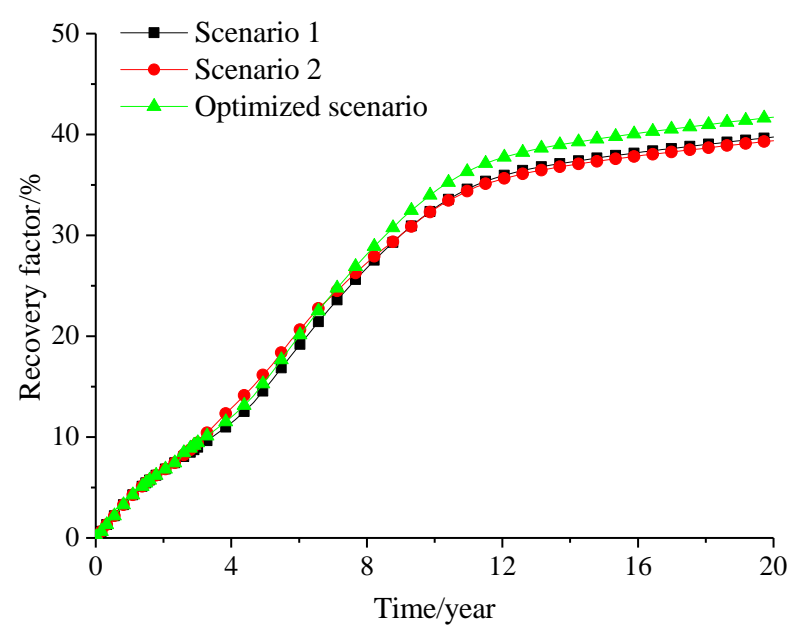

Fig. 8. Comparison of cumulative oil production before and after optimization.

The optimized scenario is compared with two other scenarios which are arbitrarily selected. Scenario 1 has a low concentration of the polymer and crosslinker, while scenario 2 has a higher one (Table 3). It can be seen that the optimized scenario has a medium concentration of polymer and crosslinker, and has an oil production increase. The recovery separately increases by $2.34 \%$ and $1.99 \%$ (Fig. 8), and the total profit increases are 3.47 million dollars and 3.15 million dollars. This reservoir development is more economical and effective.

\section{Conclusions}

1) A new method is introduced to optimize the injection concentration of polymer and crosslinker by genetic algorithm. This method does not subject to the restriction of the derivative and the function continuity, and has better global optimization ability.

2) The cross-linked polymer flooding model has been used to obtain the cumulative oil production this model can reflect the flow state of the underground fluid better than normal black oil model. The cumulative oil production is 
related to the chemical injection concentrations and the fitness function of genetic algorithm.

3) The selection of genetic parameters should be pay more attention, such as population size, crossover probability, mutation probability, and maximum generation. By adjusting them, a more accurate method can be provided based on the genetic algorithm. These optimized results can provide a theoretical basis for development scheme design.

\section{Acknowledgments}

This research was supported by "The National Major Science and Technology Projects of China, grant number: 2016ZX05033-003" and "The National Science Fund for Young Scholars of China, grant number: 41702359".

Open Access This article is distributed under the terms and conditions of the Creative Commons Attribution (CC BY-NC-ND) license, which permits unrestricted use, distribution, and reproduction in any medium, provided the original work is properly cited.

\section{References}

Albonico, P., Bartosek, M., Malandrino, A., et al. Studies on phenol-formaldehyde crosslinked polymer gels in bulk and in porous media. Paper SPE 28983 Presented at the SPE International Symposium on Oilfield Chemistry, San Antonio, Texas, 14-17 February, 1995.

Brattekås, B., Graue, A., Seright, R.S. Low salinity chase waterfloods improve performance of $\mathrm{Cr}$ (III)-acetate HPAM gel in fractured cores. Paper SPE 173749 Presented at the SPE International Symposium on Oilfield Chemistry, The Woodlands, Texas, USA, 13-15 April, 2015.

Cao, R., Cheng, L., Lian, P. Flow behavior of viscoelastic polymer solution in porous media. J. Disper. Sci. Technol. 2015, 36(1): 41-50.

Carpenter, C. Production-optimization strategy using a hybrid genetic algorithm. J. Pet. Technol. 2016, 68(12): 54-55.

Ebaga-Ololo, J., Chon, B.H. Prediction of polymer flooding performance with an artificial neural network: A twopolymer-slug case. Energies 2017, 10(7): 844.

El-Karsani, K.S.M., Al-Muntasheri, G.A., Hussein, I.A. Polymer systems for water shutoff and profile modification: A review over the last decade. SPE J. 2014, 19(1): 135-149.

Fakher, S., Bai, B. A newly developed mathematical model to predict hydrolyzed polyacrylamide crosslinked polymer gel plugging efficiency in fractures and high permeability features. Paper SPE 191180 Presented at the SPE Trinidad and Tobago Section Energy Resources Conference, Port of Spain, Trinidad and Tobago, 25-26 June, 2018.

Flory, P.J. Thermodynamics of high polymer solutions. J. Chem. Phys. 1942, 10(1): 51-61.

He, H., Wang, Y., Zhang, J., et al. Comparison of gelation behavior and morphology of resorcinolhexamethylenetetramine-HPAM gel in bulk and porous media. Transp. Porous Media 2015, 109(2): 377-392.

Himes, R.E., Ali, S.A., Hardy, M.A., et al. Reversible, crosslinkable polymer for fluid-loss control. Paper SPE 27373 Presented at the SPE Formation Damage Control Symposium, Lafayette, Louisiana, 7-10 February, 1994.

Huang, B., Zhang, W., Xu, R., et al. A Study on the matching relationship of polymer molecular weight and reservoir permeability in ASP flooding for Duanxi reservoirs in Daqing oil field. Energies 2017, 10(7): 951.

Huggins, M.L. Solutions of long chain compounds. J. Chem. Phys. 1941, 9(5): 440-440.

Jayakumar, S., Lane, R.H. Delayed crosslink polymer flowing gel system for water shutoff in conventional and unconventional oil and gas reservoirs. Paper SPE 151699 Presented at the SPE International Symposium and Exhibition on Formation Damage Control, Lafayette, Louisiana, USA, 15-17 February, 2012.

Jiang, W., Lu, X., Liu, Y., et al. An experimental study on flooding effects of chromium-organic cross-linked polymer in heavy oilfields. China Offshore Oil and Gas 2008, 20(2): 103-110. (in Chinese)

Lenchenkov, N., Glasbergen, G., Kruijsdijk, C. Flow of a cross-linking polymer in porous media. Transp. Porous Media 2018, 2018: 1-21.

Li, J., Ma, J., Liu, Y., et al. Optimizing injection parameters of polymer flooding in offshore oilfields by combining surrogate model and genetic algorithm. China Offshore Oil and Gas 2012, 24(4): 41-44. (in Chinese)

Li, X., Zhang, L., Zhang, J. Application of improved genetic algorithm to oilfield well array optimization. Petroleum Geology and Recovery Efficiency 2006, 13(2): 68-71. (in Chinese)

Li, Y., Kong, B., Li, C. Dynamic characteristics of synergistic effect between profile technology throughout flooding and ASP flooding. Acta Petrolei Sinica 2018, 39(6): 698-702. (in Chinese)

Lian, P., Tong, D., Li, L. Development of crosslinked polymer flooding in high temperature and high salt reservoirs. Advances in Fine Petrochemicals 2010, 11(7): 4-7. (in Chinese)

Liu, H., Wang, Y., Li, G., et al. An enhanced oil recovery technology continually after polymer-flooding. Paper SPE 144250 Presented at the SPE Enhanced Oil Recovery Conference, Kuala Lumpur, Malaysia, 19-21 July, 2011.

Liu, Y., Dai, C., Wang, K., et al. New insights into the hydroquinone (HQ)-hexamethylenetetramine (HMTA) gel system for water shut-off treatment in high temperature reservoirs. J. Ind. Eng. Chem. 2016, 35: 20-28.

Liu, Y., Lian, P., Tong, D., et al. Optimum design of the horizontal section length in a horizontal well using genetic algorithm. Acta Petrolei Sinica 2008, 29(2): 296299. (in Chinese)

Lu, X., Xie, K., Cao, B., et al. Study on gelling effect of $\mathrm{Cr}$ (III) polymer gel and its influence factors. Journal of China University of Petroleum 2015, 39(3): 170-176. (in Chinese)

Luo, Y., Zhang, Y., Dang, J. Laboratory study of HPAM/Cr(III) weak gel and profile control system. Journal of Yangtze UNiversity (Nat Sci Edit) 2005, 2(4): 311-313. (in Chinese) 
Melanie, M. An Introduction to Genetic Algorithms. Cambridge, England, The MIT Press, 1998.

Mody, B.G., McKitrick, R.S., Shahsavari, D. Proper application of crosslinked polymer decreases operating costs. Paper SPE 17288 Presented at the Permian Basin Oil and Gas Recovery Conference, Midland, Texas, 10-11 March, 1988.

Montes, G., Bartolome, P., Udias, A.L. The use of genetic algorithms in well placement optimization. Paper SPE 69439 Presented at the SPE Latin American and Caribbean Petroleum Engineering Conference, Buenos Aires, Argentina, 25-28 March, 2001.

Nguyen, T.Q., Green, D.W., Willhite, G.P., et al. Effect of composition of a polyacrylamide-chromium(III) acetate gel on the magnitude of gel dehydration and disproportionate permeability reduction. Paper SPE 89404 Presented at the SPE/DOE Symposium on Improved Oil Recovery, Tulsa, Oklahoma, 17-21 April, 2004.

Pope, G.A., Nelson, R.C. A chemical flooding compositional simulator. Soc. Pet. Eng. J. 1978, 18(5): 339-354.

Pope, G.A., Sepehrnoori, K., Sharma, M.M., et al. Threedimensional NAPL fate and transport model. 1999.

Shen, D., Li, W., Jin, D., et al. Shuanghe Oilfield VII upper test displacement effect of temperature and salt resisting crosslinked polymer and understanding. J. Oil Gas Technol. 2010, 32(5): 326-328.

Shriwal, P., Lane, R.H. Impacts of timing of crosslinker addition on water shutoff polymer gel properties. Paper SPE 153241 Presented at the SPE Improved Oil Recovery Symposium, Tulsa, Oklahoma, USA, 14-18 April, 2012.

Song, W., Zeng, X., Yao, H., et al. Application of a new crosslinked polymer displacement technology at Bo-19 Block in Gudao oilfield. Paper SPE 77797 Presented at the SPE Asia Pacific Oil and Gas Conference and Exhibition, Melbourne, Australia, 8-10 October, 2002.

Wang, J., Sheng, P., Li, Z., et al. Experimental investigation of crosslink polymer plugging in horizontal heterogeneous reservoir. Acta Petrolei Sinica 2002, 23(3): 60-64. (in Chinese)
Wang, X., Cao, L. Genetic algorithms-theory, applications and software implements. Xi'an, China, Xian Jiaotong University press, 2002. (in Chinese)

Wei, C. Organic cross-linked polymer flooding test injection in Shengtuo high temperature and high salinity reservoir. Petroleum Geology and Recovery Efficiency 2007, 14(5): 69-71. (in Chinese)

Wood, D.A. Dual objective oil and gas field development project optimization of stochastic time cost tradeoff problems. Adv. Geo-Energy Res. 2018, 2(1): 14-33.

Xie, C., Guan, Z., Blunt, M., et al. Numerical simulation of oil recovery after cross-linked polymer flooding. J. Can. Pet. Technol. 2009, 48(4): 37-41.

Yang, J., Xie, X., Zhang, J., et al. Injection parameters optimization of cross-linked polymer microspheres and polymer composite flooding system. Pet. Explor. Dev. 2014, 41(6): 794-797.

Yin, X., Wang, L., Jin, Y., et al. The parameter optimal design of whole block water-plug and profile control after polymer flooding. Sci. Technol. Eng. 2013, 13(5): 1285-1288.

Yuan, F., Mu, T., Wei, C. A fast solution to the mathematical model of cross-linked polymer flooding. Journal of Southwest Petroleum Institute 2014, 36(6): 128-134. (in Chinese)

Zhang, G., Liu, D., Liu, Z., et al. Determining injection parameters of crosslinked polymerflood slug by using optimization method. J. Oil Gas Technol. 2010, 32(1): 136-140.

Zheng, B., Hou, J., Zhang, M., et al. Research on oil displacement mechanism of crosslinked polymer using CT technique. Xinjiang Petroleum Geology 2016, 37(1): 97-101. (in Chinese)

Zhou, Y., Guo, J., Wang, T., et al. A high temperature and high salinity resistant particulated precrosslinked gel and its use for reservoir permeability adjustment. Oilfield Chem. 2007, 24(1): 75-78. 